\title{
Capítulo
}

3

\section{Automação Cognitiva de Processos com UiPath}

\author{
Rafael Oliveira de Faria, Tiago Luis de Andrade e José Ahirton Batista \\ Lopes Filho
}

\begin{abstract}
In the corporate environment there are still many processes which are not integrated with different systems, making human intervention necessary. We see this mainly in processes such as the capture, interpretation and distribution of information which are not integrated. In parallel, we live daily with various forms of artificial intelligence that help us by being present in the most different tools. In this context, through intelligent automation, we can increasingly enable repetitive processes within a defined context. Thus, in this chapter, we seek to portray a scenario where we use process automation through a cognitive tool, demonstrating possible applications in RPA to perform tasks traditionally performed by humans.
\end{abstract}

\section{Resumo}

No meio corporativo ainda existem muitos processos os quais não estão integrados para com diferentes sistemas, fazendo com que haja a necessidade da intervenção humana. Vemos isso principalmente em processos tais como a captura, interpretação $e$ distribuição de informações as quais não estão integradas. Em paralelo, convivemos diariamente com diversas formas de inteligências artificiais as quais nos auxiliam estando presentes nas mais diferentes ferramentas. Nesse contexto, por meio da automação inteligente, podemos cada vez mais viabilizar processos repetitivos conforme um contexto definido. Dessa forma, neste capítulo, buscamos retratar um cenário onde realizamos o uso da automação de processo por meio de de uma ferramenta cognitiva, demonstrando possíveis aplicações em RPA para a execução de tarefas tradicionalmente executadas por humanos. 


\subsection{Introdução}

A humanidade vive uma constante busca de aprimoramento de tudo que está ao seu redor. Atualmente temos dispositivos moveis inteligentes capazes de processar diversas informações importantes em poucos milésimos de segundos. Entretanto, todo esse poder de processamento não elimina o fator humano no qual estamos inseridos.

Em um ambiente administrativo, seja no setor público ou privado, periodicamente nos deparamos com processos repetitivos, no qual uma pessoa é instruída a ler e compreender determinadas informações de uma fonte de dados, e repassar sua compreensão, ou até mesmo transcrever, dados importantes para uma segunda fonte.

Tendo em vista esse cenário, podemos notar de forma empírica que, em um ambiente administrativo, existem diversos trabalhos repetitivos, onde pessoas executam um trabalho meramente operacional, e poucas vezes atuam de forma analítica. Em tempos atuais deve-se levar em consideração a existência de inteligências artificiais capazes de ler, escutar e mensurar dados de diversas fontes.

Nesse contexto, nos deparamos com duas abordagens: Lean Six Sigma e a Lean Manufacturing. A primeira trabalha com a busca contínua pela perfeição, que acontece com a diminuição do desvio padrão, medida que indica o grau de variação de um conjunto de valores em relação à média. A segunda é um método operacional que visa reduzir e eliminar os desperdícios na produção de uma empresa de forma contínua, com a implementação de ferramentas de qualidade [PETENATE, 2019].

Corporações modernas buscam uma melhoria contínua baseada no Lean Six Sigma, visando reduzir seus processos administrativos, levando em conta o impacto positivo dessa redução, uma vez que o resultado esperado é alcançado.

Sendo assim, podemos aplicar ambos os conceitos para o melhoramento de processos administrativos, junto com uma equipe de automação, em que todas as ações poderão ser planejadas e integradas com fluxos de trabalhos otimizados, mantendo um padrão de produção.

Levando em consideração esse contexto, criamos um ambiente no qual há a simulação de um processo administrativo, com o objetivo de comparar o desempenho de um usuário e um robô, a saber: o acesso, captura, interpretação e envio dos dados; apresentando a taxa de execução e o tempo de produção frente do cenário apresentado.

\subsection{Robotic Process Automation - RPA}

A IEEE Standards Association publicou em 2017 o guia IEEE 2755-2017 para Termos e Conceitos em Automação Inteligente de Processos. Por se tratar de uma abordagem nova, a IEEE busca definir essa abordagem.

Uma família totalmente nova de tecnologias inteligentes de automação de processos baseadas em software surgiu recentemente. Devido à novidade desse tipo de capacidade de automação, não existem definições comuns de conceitos, capacidades, termos, tecnologia, tipos, etc [IEEE, 2019].

Algumas dessas tecnologias são baseadas em software, como o RPA, segundo van der Aalst, 2018. RPA é um termo genérico para ferramentas que operam na interface do usuário de outros sistemas de computadores da maneira que um ser humano faria. O RPA 
tem como objetivo substituir as pessoas pela automação feita de maneira externa [van der Aalst, 2018].

Essa é uma tecnologia relativamente nova que automatiza processos baseados em regras, mas luta para lidar com dados não estruturados e qualquer tomada de decisão [BURGESS, 2018].

O termo "Automação Robótica de Processos" conota visões de robôs físicos vagando pelos escritórios executando tarefas humanas. $\mathrm{O}$ termo realmente significa automação de tarefas de serviço que anteriormente eram executadas por seres humanos [MADAKAM, HOLMUKHE and JAISWAL, 2019].

Seguindo a publicação do Institute of Electrical and Electronics Engineers, o mesmo retrata RPA como um software pré configurado que pode compor elementos de inteligência artificial, mas a sua principal função se baseia em executar instruções autônomas sobre processos humanos.

Instância de software pré-configurada que usa regras de negócios e coreografia de atividades predefinidas para concluir a execução autônoma de uma combinação de processos, atividades, transações e tarefas em um ou mais sistemas de software não relacionados para fornecer um resultado ou serviço com gerenciamento de exceções humanas [IEEE, 2019].

Segundo o site da UiPath, os robôs RPA utilizam a interface do usuário para capturar dados e manipular aplicativos, assim como os humanos. Eles interpretam, acionam respostas e se comunicam com outros sistemas para executar uma grande variedade de tarefas repetitivas [UiPath, 2019].

A Inteligência Artificial - IA pode fazer muitas coisas, mas não pode fazer tudo. Muitas vezes, a implementação de uma solução de IA autônoma atenderá aos objetivos que você deseja alcançar [BURGESS, 2018].

Ao automatizar processos com RPA, iniciamos uma nova camada de software, a qual replica as instâncias de trabalho baseando-se em regras humanas.

Para maior clareza, é importante diferenciar o RPA dos sistemas de TI tradicionais. O RPA, em seu nível mais básico, utiliza a tecnologia para substituir uma série de ações humanas, fator de entrada da terminologia 'robô' [BURGESS, 2018]. Entre as suas diversas vantagens podemos citar a redução do custo e gastos efetivos em um processo rotineiro.

A automação de processo robótico pode substituir quase todo o trabalho transacional que o ser humano realiza, a um custo muito menor, que poder chegar a $50 \%$ [BURGESS, 2018].

Apesar do impacto trabalhista na substituição do trabalho transacional, o trabalho analítico, critico e criativo passará a predominar, sendo assim, com toda revolução industrial e o surgimento de novas tecnologias, também surgem novas profissões. 


\subsection{Processo de Automação}

Existem algumas ferramentas RPA no mercado, segundo o Gartner o UiPath é uma fermenta com grande potencial se destacando entre outras no mercado, em 2019 o Gartner fez o primeiro comparativo dessas ferramentas, como podemos visualizar na figura 1.1.

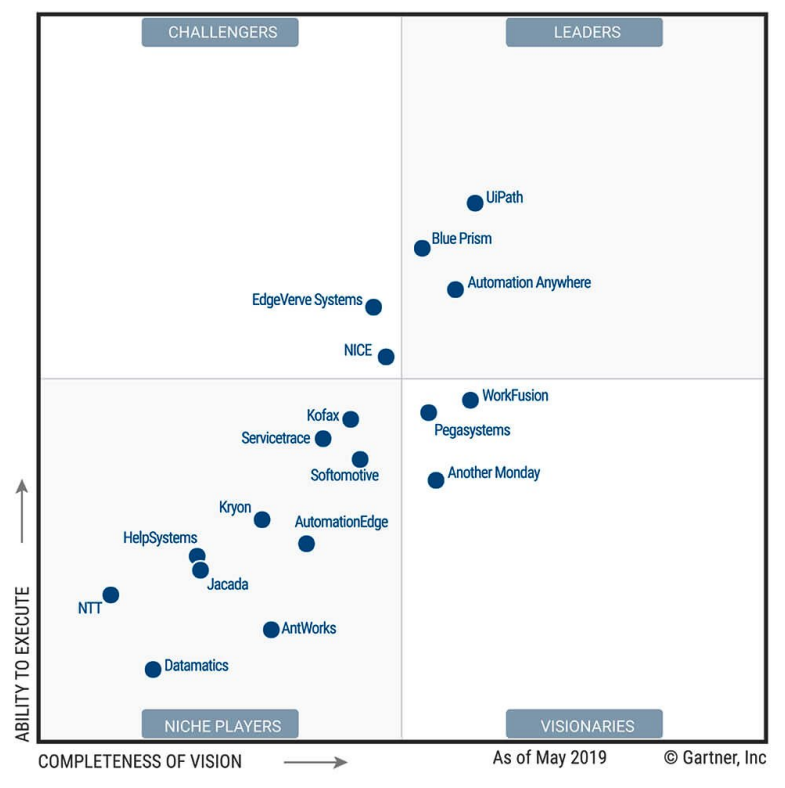

Figura 1.1. Quadrante Mágico Gartner

Não vamos adentrar no mérito avaliativo em comparar as ferramentas presente no Gartner, apenas faremos uso do UiPath durante nossa demonstração. Mas antes de iniciarmos quaisquer implementações, precisamos analisar o cenário no qual vamos executar uma implementação, visando o desempenho frente e os riscos que essa implementação pode proporcionar a corporação que esteja executando esse desenvolvimento.

Analisar o processo ajuda a conformidade do processo, matando a qualidade da implementação; também ajuda a compreender as necessidades operacionais e até reduzir passos em processos extensos; consequentemente, já avaliamos os riscos no investimento de tempo e custos da implementação, avaliando a real necessidade de uma automação do processo; e por fim podemos manter uma melhoria continua das etapas do processo, sem precisar alterar o processo como um todo.

Ao analisarmos todo um processo que será automatizado, se faz necessário definir os procedimentos que serão executados, dessa forma o UiPath lista os seguintes tópicos que um procedimento precisa explicar:

- quem é responsável por cada parte do processo

- quando cada parte do processo precisa ocorrer

- como lidar com exceções

- especificações aplicáveis a cada parte do processo 
Dessa forma, conseguimos manter uma consistência durante toda implementação do processo e procedimento. Para que tudo isso seja possível, devemos manter uma ponte entre os stakeholders que solicitam soluções, com aqueles que entregam essas soluções, o time de analistas e desenvolvedores.

Sendo assim, os analistas de negócios buscam compreender os proprietários do processo, e todo requisição e problema apresentado, como está apresentado na figura 1.2.

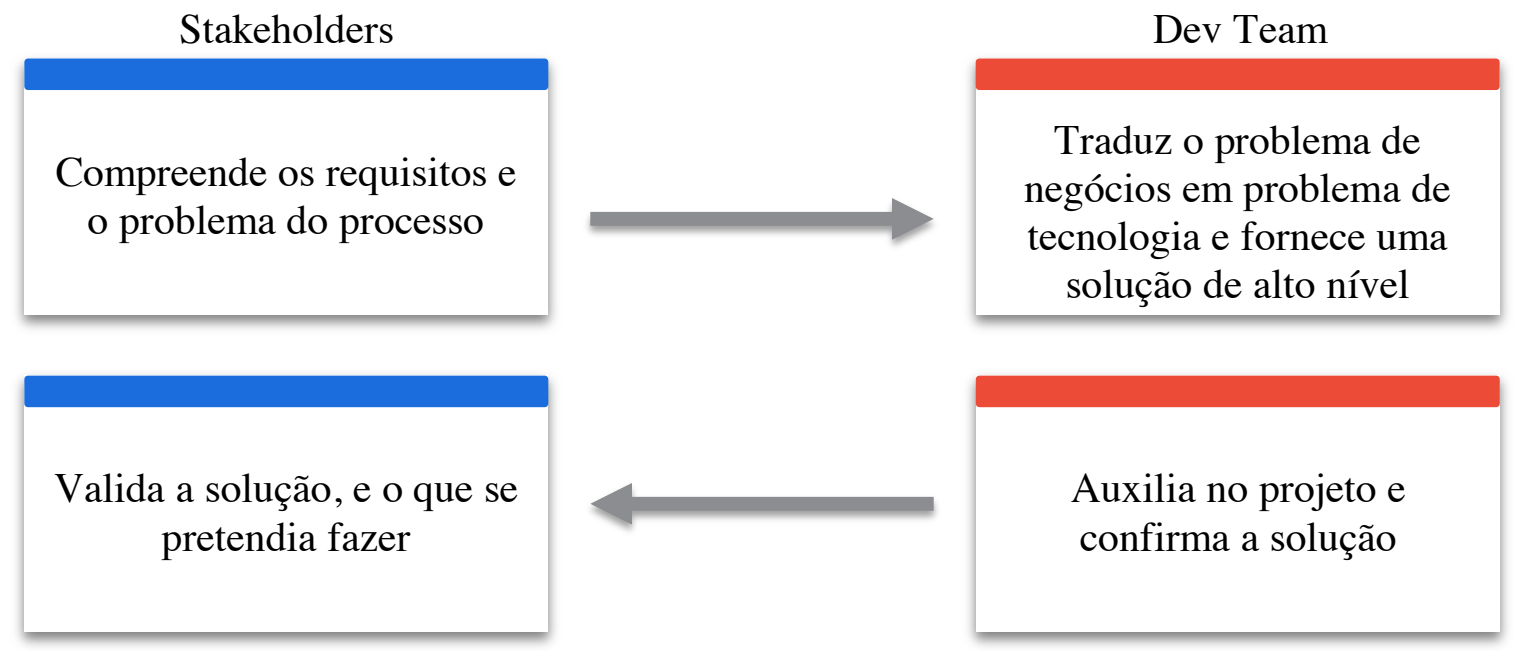

Figura 1.2. Ponte entre Stakeholders e Dev Team

Para a realização desse trabalho, é preciso ter habilidades durante todo levantamento de requisitos e desenvolvimento, uma vez que todo time deve manter uma comunicação clara e transparente sobre as etapas dos processos e procedimentos.

\subsection{Introdução ao UiPath}

As ferramentas utilizadas para implementação de RPA são relativamente novas no mercado referente ao ano de 2019, com o UiPath não é diferente. Dessa forma, essas ferramentas são constantemente atualizadas, seja para implementar novos recursos, corrigir novas falhas, ou até alterar suas políticas de uso.

Partindo desse princípio, algumas informações presentes nesse capítulo podem sofrer alterações, sendo assim, buscamos apresentar funcionalidades de uso comum buscando evitar o desencontro de informações, ressaltando que aplicamos nossos testes na versão community UiPath Studio 2019.10.0-beta.377.

\subsubsection{Sobre UiPath}

Em 2019 o UiPath atingiu a marca impressionante de usuários de suas ferramentas, com mais de 400 mil usuários, atualmente a ferramenta possui três principais produtos, voltados para desenvolvimento, execução e gestão de bot (robôs).

Dentre os produtos, temos o UiPath Studio, uma ferramenta voltada para o desenvolvimento de toda lógica da regra de negócio que será implementada, como podemos ver na figura 1.3 (fluxo implementado). 


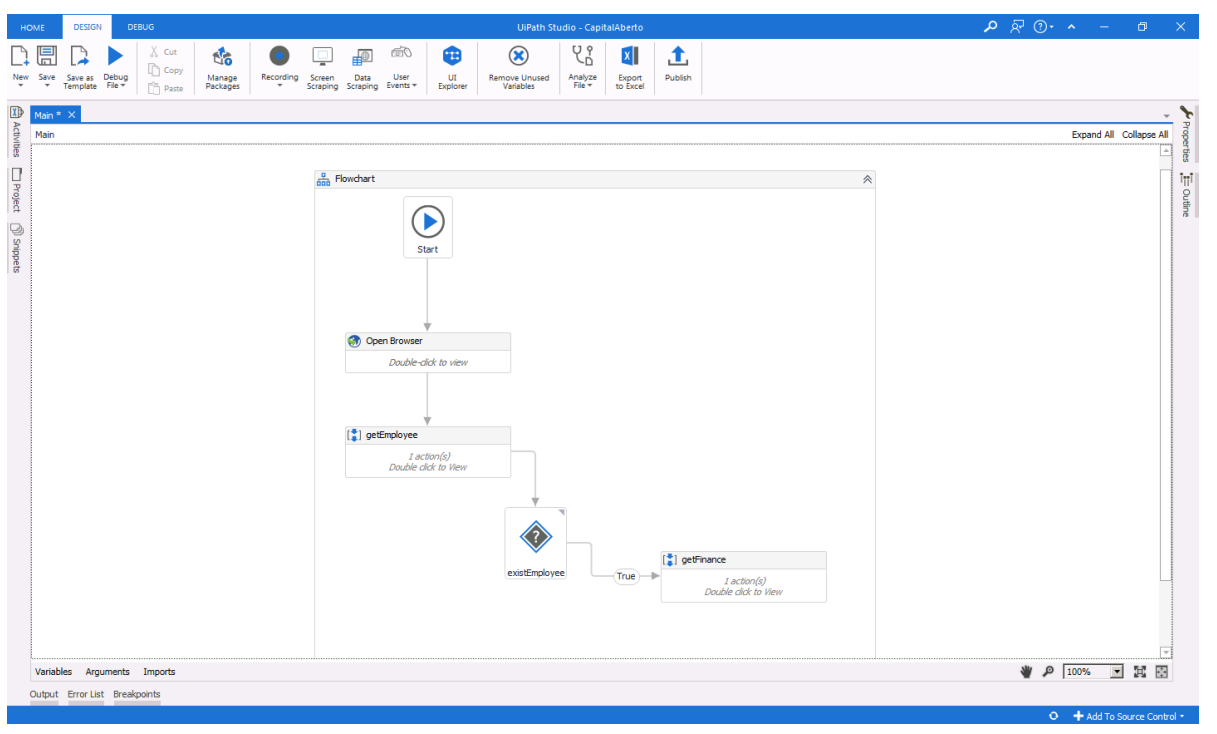

Figura 1.3. Fluxo Implementado

Como podemos visualizar na figura acima, o UiPath Studio Community com um fluxo de trabalho implementado. Para distribuição e execução desse robô, podemos utilizar o UiPath Orchestrator, que possui um painel centralizado para gerenciar e implantar os robôs em escala. Essa distribuição é realizada através do UiPath Robots, que é executada no cliente para executar as rotinas e os robôs que é gerenciável remotamente através do Orchestrator.

Ambas ferramentas tem a versão comunidade com suas limitações, e o uso de todas esses serviços em conjunto, exige uma alta carga de trabalho, sendo assim, vamos enfatizar o UiPath Studio, pois é a ferramenta de entrada para o exercício do conhecimento e desenvolvimento de RPA.

\subsubsection{UiPath Studio Community}

Nesse momento vamos conhecer alguns recursos básicos que podemos utilizar como base em nossa linha de aprendizagem, buscando iniciarmos os estudos nessa ferramenta, para que possamos implementar diversos trabalhos futuros.

Ao abrirmos o UiPath Studio, podemos visualizar que a sua estrutura de navegação é divida em dois macros, sendo o painel de navegação alinhado a direito com o fundo azul, e o painel de navegação centralizado com o fundo branco, como está presente na figura 1.4 (Navegação inicial UiPath Studio). 


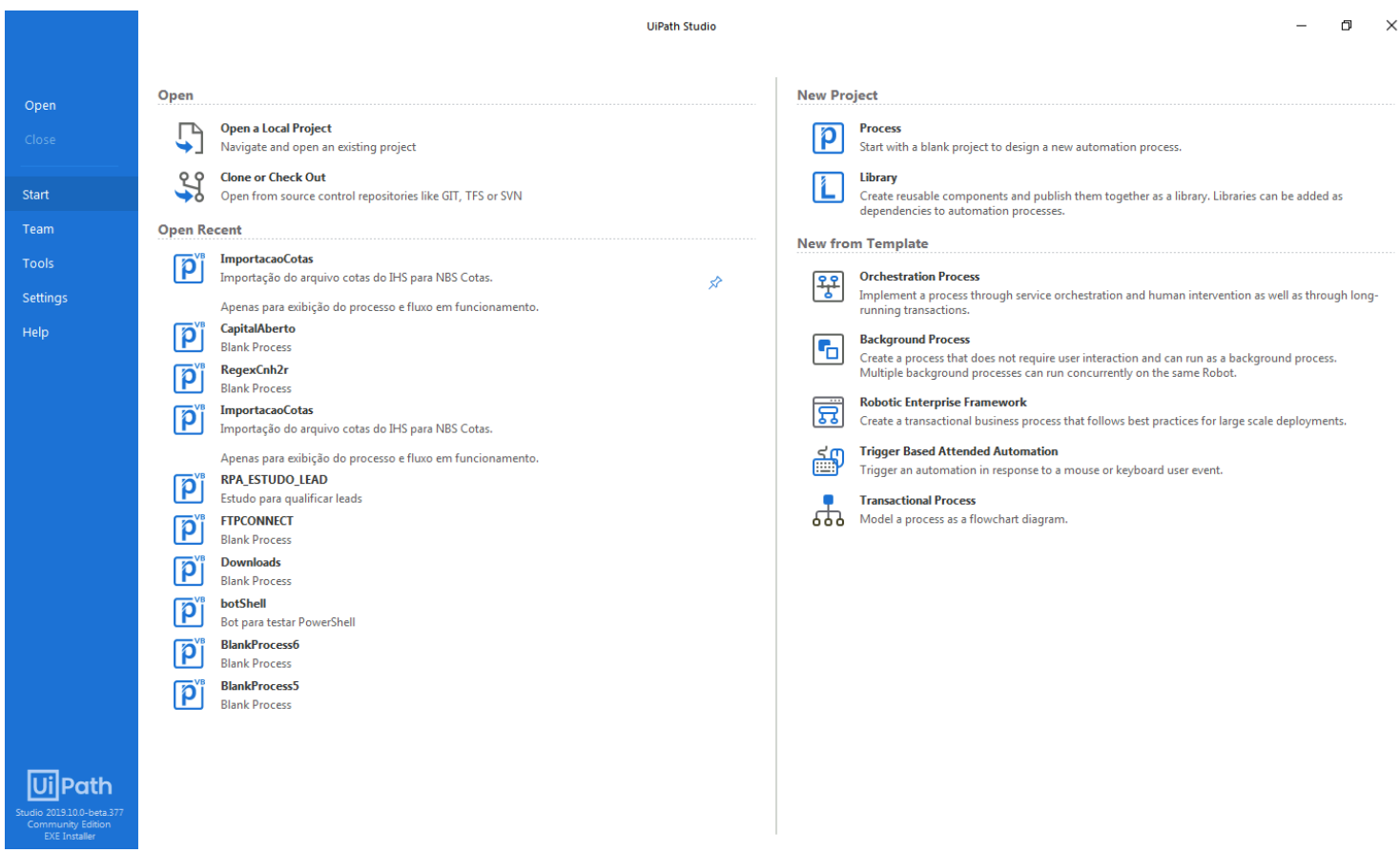

Figura 1.4. Navegação inicial UiPath Studio

O menu de navegação centralizado acaba se tornando autoexplicativo com suas legendas claras e objetivas, contendo uma breve descrição abaixo de opção presente na tela, observe que até os projetos abertos recentemente contém descrições sobre o que é possível realizar com aquele projeto.

Já no menu de navegação a direita, possui apenas palavras chaves para direcionar a navegação, dessa forma, podemos visualizar sua descrição na tabela 1.1 (Descrição do Menu).

Tabela 1.1. Ponte entre Stakeholders e Dev Team

\begin{tabular}{|c|l}
\hline Open & $\begin{array}{l}\text { Nessa opção podemos buscar e abrir projetos salvos no dispositivo } \\
\text { que não estão presentes na nossa lista de abertos recentes. }\end{array}$ \\
\hline Start & $\begin{array}{l}\text { Podemos iniciar um projeto, seja ele um novo projeto, ou um projeto } \\
\text { com base em um template, ou até mesmo projetos que estão em } \\
\text { algum repositório, além de podemos abrir projetos recentes. }\end{array}$ \\
\hline Team & $\begin{array}{l}\text { Em Team, é possível gerenciar seus projetos com base nos } \\
\text { repositórios GIT, SVN e TFS, podendo trabalhar em equipe. }\end{array}$
\end{tabular}




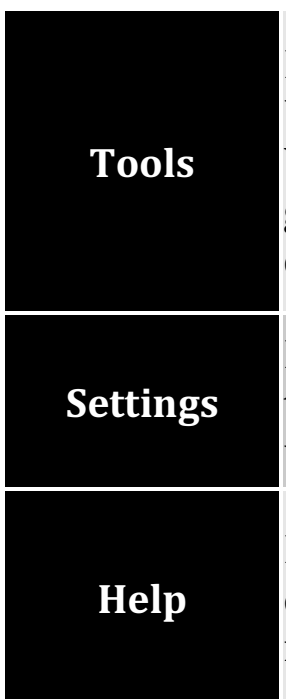

Para que possamos fornecer o máximo de integridade no uso do UiPath Studio, devemos nos conectar com o mais diverso tipo de browsers e aplicações, para isso basta ir em tools e instalar ou gerenciar suas dependências, e efetuar downloads das extensões que serão utilizadas durante a navegação.

Nas configurações podemos personalizar nosso ambiente de trabalho, e também visualizar o tipo de licença que está sendo utilizado.

Por fim, ao pedir ajuda, somos direcionados para documentação e comunidade do UiPath, tendo acesso também ao centro de ajuda, notas de atualizações e ambiente para certificações.

Com base nessa navegação, podemos implementar diversos projetos distribuídos e colaborativos, no entanto, vamos explorar alguns dos elementos presente no processo de desenvolvimento, com base no fluxo a ser implementado no próximo tópico.

\subsection{Implementando fluxograma de busca com Google Finance}

A partir do aspecto de navegação apresentado anteriormente, podemos iniciar um novo processo, utilizando o fluxo presente na figura 1.5 (Fluxo do Processo).

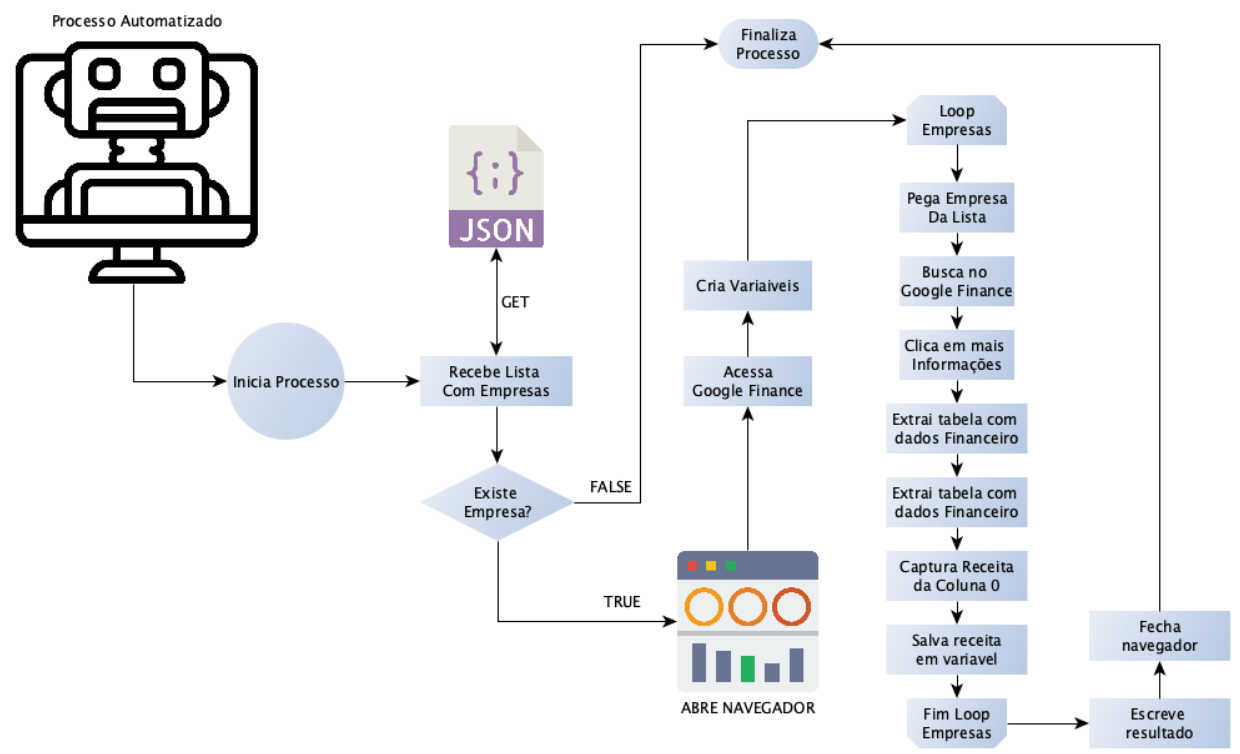

Figura 1.5. Fluxo do Processo 
A partir do fluxo de processo apresentando na imagem acima, podemos compreender os passos que o robô deve executar, até que concluir esse processo. Dessa forma, a partir do menu de navegação apresentado na tabela 1.1, vamos iniciar um novo processo, como está apresentado na figura 1.6 (Criando um novo processo).

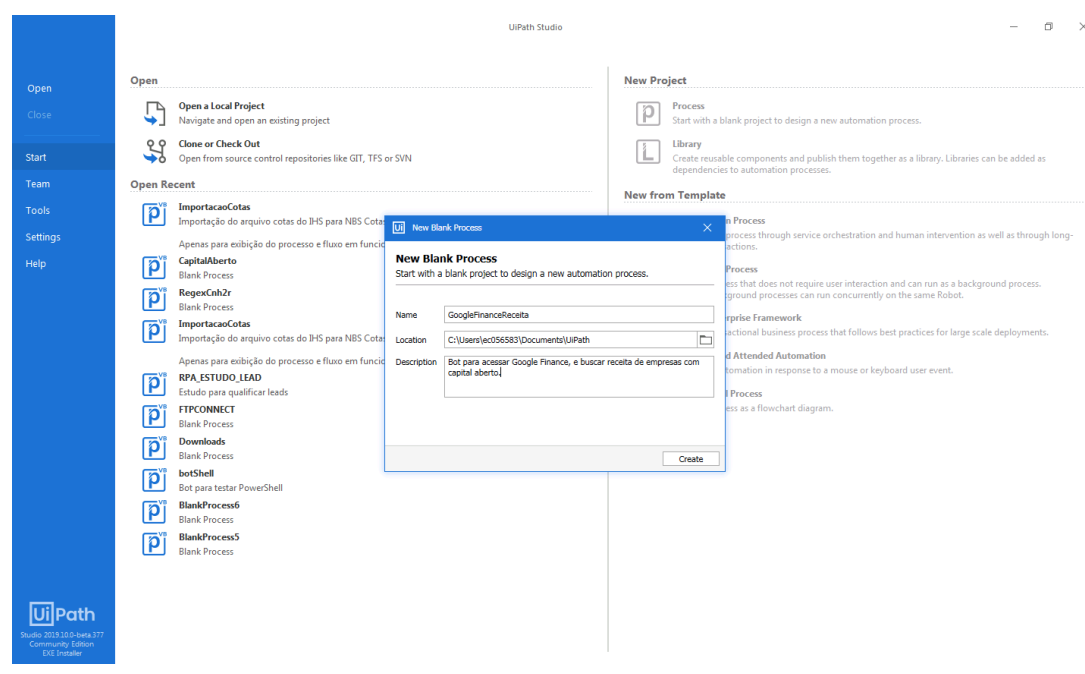

Figura 1.6. Criando um novo processo

Ao criar um novo projeto, precisamos indicar o local onde seu projeto será armazenado, o nome do projeto e uma breve descrição para que possamos identificá-lo posteriormente.

O processo de implementação pode ser visualizado na figura 1.3 (Fluxo implementado), onde criamos um novo Flowchart, e fazemos todas as etapas necessário para o funcionamento do processo, o fonte implementado pode ser visualizado no repositório do GitHub através do link $<$ https://github.com/rafaeloliveirafaria/GoogleFinance>, assim, todo o fonte estará disponível em sua área de trabalho, pronto para ser utilizado. Para utilizar o repositório, basta navegar até a aba Team, conforme apresentado na tabela de menu de navegação (1.1), e em seguida seguir os passos da figura 1.7 (Clonando repositório).

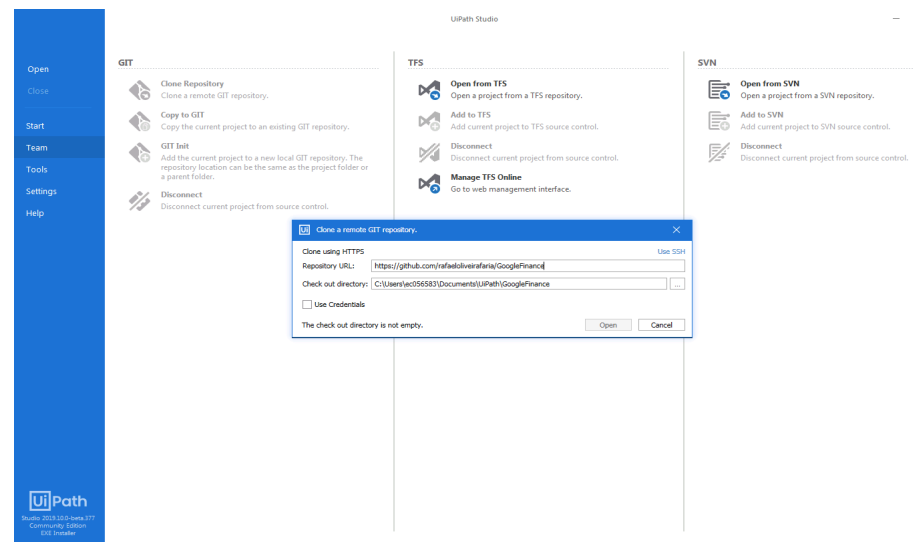

Figura 1.7. Clonando repositório 
Ao clonar esse projeto, é possível visualizar as sequencias implementadas no processo. Na sequência getFinance, pode notar que existe um instancia que percorre um array de string, e passa via argumento o valor encontrado, como pode ser visto na figura 1.8 (Percorre empresas).

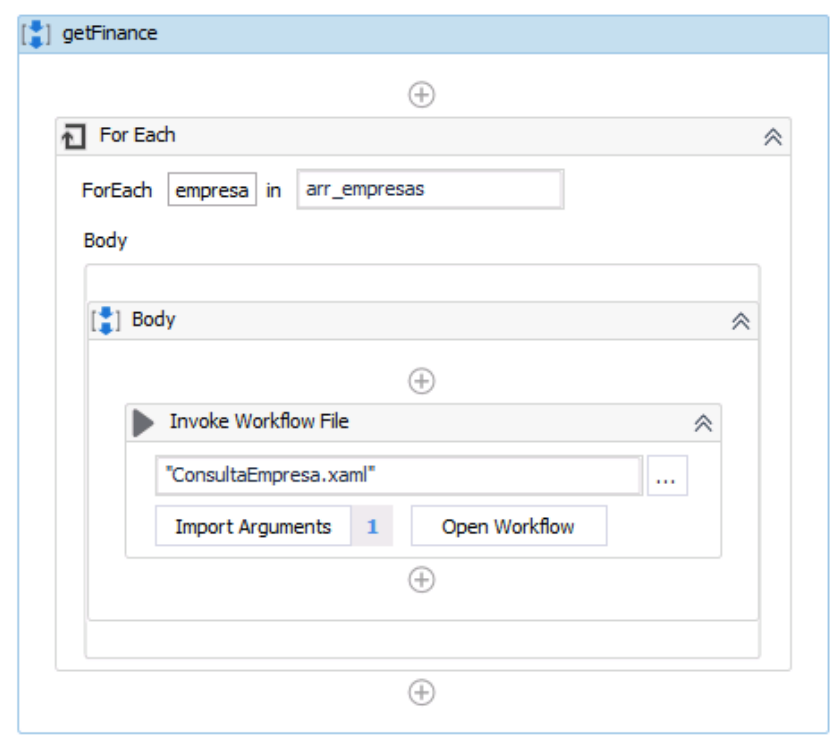

Figura 1.8. Percorre empresas

No arquivo ConsultaEmpresa.xaml contém as etapas de navegação, simulando o comportamento humano para navegar pelo Google Finance, consultando as empresas que estão sendo passadas por argumento. Na prática, com a extensão do UiPath para navegador, conseguimos mapear os meta dados, e informar quais os parâmetros da página que será utilizado, podendo assim utilizarmos meios estáticos ou dinâmicos para esse mapeamento, nesse caso seguindo a figura 1.9 (Campo de pesquisa), podemos visualizar que capturarmos a tag do tipo input, com um id (identificador) especifico.

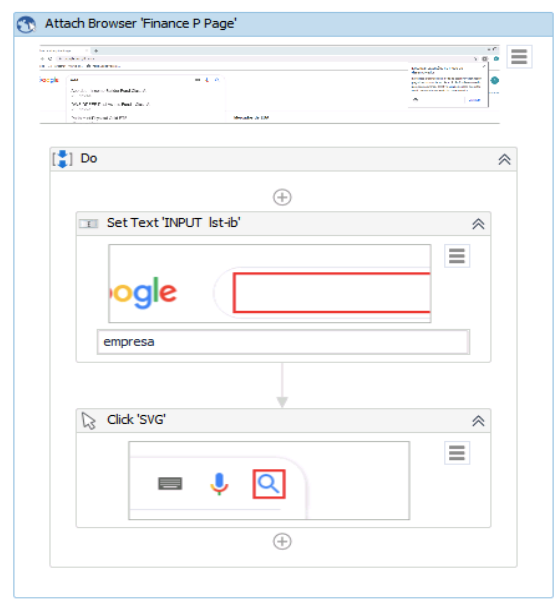

Figura 1.9. Campo de pesquisa 
Assim, ao identificarmos a página de navegação podemos iniciar a consulta inserindo na tag input o nome da empresa que foi passado por argumento, e posteriormente clicar em pesquisar, como está sendo apresentado na figura 1.10 (Navegação Automatizada).

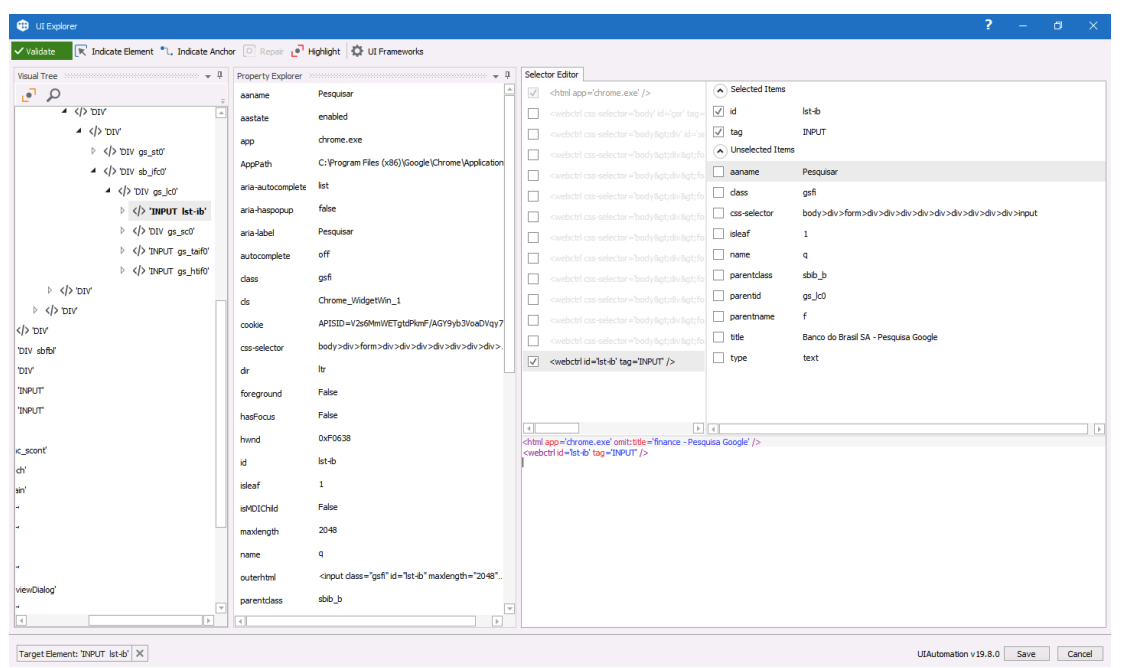

Figura 1.10. Navegação Automatizada

A partir dos princípios de utilização da ferramenta podemos navegar por elementos presente nas aplicações que está sendo utilizado em um determinado processo. Com isso conseguimos mapear as informações de navegação extraindo os dados ali presente, como apresentado na figura 1.11 (Extraindo dados Financeiro).

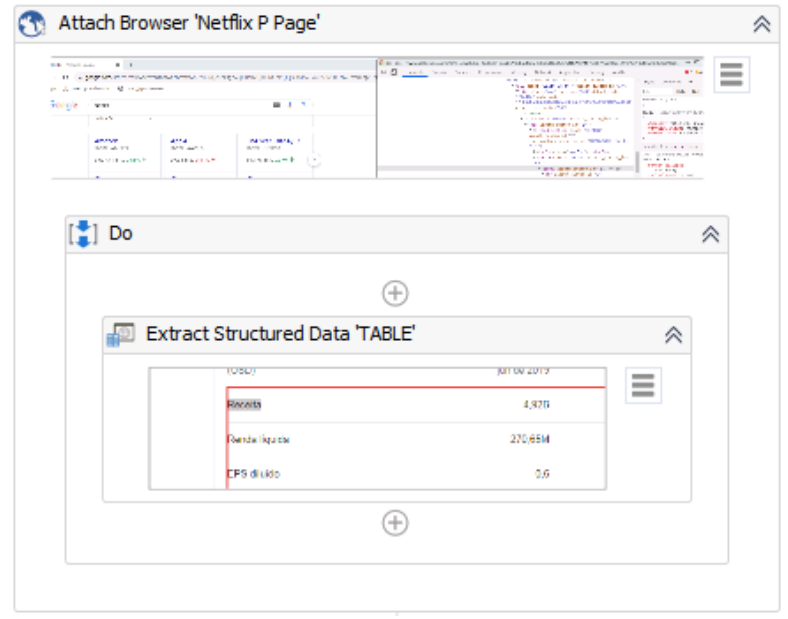

Figura 1.11. Extraindo dados Financeiro

Com os dados extraído, basta percorrermos a tabela de informação, pegar os dados que seja do interesse do desenvolvedor e armazená-las em variais. A aplicação e distribuição desses dados pode ter inúmeros desfechos, sendo necessário apenas programar como deve ser realizado sua distribuição, lembrando que a própria ferramenta do UiPath, fornece ambientes configuráveis para enviar e-mail, abrindo um canal de comunicação direto com o robô. 


\subsection{Considerações Finais}

A constante evolução tecnológica fez com que a evolução industrial fizesse parte da nossa sociedade como um todo. Temas que eram vistos como futurísticos, pode ser considerado realidade. Diante desses fatos, surge uma pergunta: estamos tão evoluídos como as ficções de Isaac Asimov? Talvez, não sabemos. A única certeza é que o futuro já é o agora, e nesse presente em que vivemos, contamos com diversas Inteligências Artificiais para nos auxiliar, não apenas no entretenimento, mas no nosso cotidiano de trabalho.

Frente a esse momento de transação de cargos e funções, podemos analisar que os robôs auxiliadores em processos digitais se tornaram praticamente inevitável, e que agora é uma questão de tempo e adequação para que estejam presentes em quase todo o comércio.

Apesar da estranheza compreensiva pelo nível de compatibilidade com o trabalho humano, há uma compreensão que o robô substituirá funções executadas pelo homem, principalmente aquelas operacionais.

Por mais que comparemos o desempenho e a disponibilidade de um robô - oras, robô não tira férias - em momento algum exercemos a comparação analítica, crítica e principalmente criativa, frente a cenários relativo ao mundo analógico e o digital, pois a capacidade sensorial de captar a sensibilidade do momento em que vive equivale a um comportamento humano.

Enfim, talvez devemos desfrutar dessas tecnologias com louvor, uma vez que os robôs nos proporcionam uma liberdade criativa, no qual poderemos dedicar o nosso tempo para executarmos uma análise minuciosa de todos os processos que presenciamos, trazendo à tona o lado criativo daqueles que até então ficam presos na rotina de replicar informações. Com isso, o RPA busca agilizar todo processo humano que esteja vinculado a uma rotina digital.

\section{References}

Burgess, Andrew. (2018) "The Executive Guide to Artificial Intelligence: How to identify and implement applications for AI in your organization', Palgrave Macmillan. London, United Kingdom, $1^{\circ}$ edição.

IEEE, (2017) “IEEE 2755-2017 - IEEE Guide for Terms and Concepts in Intelligent Process Automation', https://standards.ieee.org/standard/2755-2017.html, Agosto.

Petenate, Marcelo. (2019) "Aprenda Tudo Sobre a Metodologia Lean Six Sigma, Detalhes, Certificação e como Aplicar', https://www.escolaedti.com.br/lean-e-seissigma-qual-a-diferenca, Agosto.

Madakam, Somayya., Holmukhe, Rajesh M. and Durgesh Kumar Jaiswal. (2019) “THE FUTURE DIGITAL WORK FORCE: ROBOTIC PROCESS AUTOMATION (RPA)", In: Journal of Information Systems and Technology Management - Jistem USP, Vol. 16, 2019, DOI: 10.4301/S1807-1775201916001.

van der Aals, Wil M. P., Bichler, Martin., Heinzl, Armin. "Robotic Process Automation’, In: Bus Inf Syst Eng 60(4), 2018, DOI: 10.1007/s12599-018-0542-4. 